\section{Cocaine, Sex and Physicians}

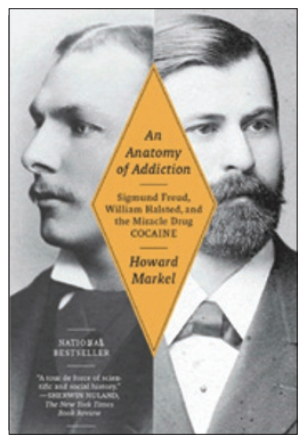

\section{An Anatomy of Addiction: Sigmund Freud, William Halsted, and the Miracle Drug Cocaine \\ Howard Markel}

Pantheon, 2011

352 pp., hardcover, $\$ 28.95$

ISBN: 0375423303

\section{Reviewed by John Mendelson}

Howard Markel's wonderful book An Anatomy of Addiction: Sigmund Freud, William Halsted, and the Miracle Drug Cocaine is a rare treat that excels on several planes. Markel, a physician and professor of history at the University of Michigan, has crafted a book that is both a learned history and a salacious read. He tells the story of two of the most important physicians of the last 200 years: Sigmund Freud and William Stewart Halsted. And the story he tells is one of brilliance, invention and ambition intertwined with drugs, sex and near catastrophe. Markel chronicles the nineteenth century discovery by Europeans of cocaine and describes the purification and commercialization of the drug by European and American chemists. He then uses Freud's and Halsted's stories to delve into the complexities of drug abuse and the development of addiction and to illuminate the origins of our systems for understanding and treating surgical and psychiatric diseases.

Freud is a household name-who hasn't heard of the unconscious or psychoanalysis? Halsted, in contrast, although perhaps less well known than Freud to the layperson, laid the foundations for modern surgical technique and practice. He invented many basic suturing techniques and operations (such as the radical mastectomy) that are still in use and was the first to insist on sterile operating fields and clean clothing-if you have ever worn a surgical scrub, you can thank Halsted. Along with William Osler, William Welch and Howard Kelly, he was one of the four founding physicians of the Johns Hopkins Hospital. What is less well known is that both Freud and Halsted were cocaine addicts.

We meet Freud and Halsted as young, ambitious and personable physician-scientists and follow their separate stories as cocaine initially helps, but then nearly destroys, their careers and lives. Each started using cocaine as a therapeutic drug-Freud for its mood-altering properties and Halsted as a local anesthetic - and, through self-experimentation, both became addicted. Freud conducted and published human studies, often as both the subject and investigator, where he came to believe that cocaine was a wonder drug that could cure most anything. Along with Wilhelm Fliees, an early pioneer in otolaryngology, he promoted a bizarre theory that the nose is the most important organ in the body, directly regulating health and human sexuality. Together, they treated scores of patients with intranasal cocaine, nearly killing some and addicting many.

Although Freud did not appear to suffer long-term complications of his addiction, Halsted paid a huge personal price for his experimentation with cocaine. He ended up as the first patient admitted to an insane asylum for cocaine addiction and suffered a complete change in personality due to regular use of cocaine. Interestingly, Freud promoted and tested the use of cocaine to treat opiate addiction, but for Halsted opiates became the substitute for cocaine that allowed him to function in society; he injected $\sim 200$ mg of morphine every day for most if not all of his time as the Chief of Surgery at Hopkins. Thus, Halsted also has the unique distinction of being the first person to demonstrate the efficacy of opiate substitution therapy.

What would a tell-all story be without sex? It turns out that Freud and Halsted had complex sex lives: Freud was bisexual and Halsted was almost certainly gay. It seems Freud was at his most libidinous while using cocaine; only after quitting was he able to maintain the stable family life that allowed him to produce his best work. Halsted, following the death of his presumed lover, descended into a deeper dependence on cocaine. Consistent with what we know today about the consequences of addiction on relationships, Halsted seems to have been unable to form any lasting intimate relationships for the remainder of his life, an observation supported by a late-in-life marriage of convenience that seemed designed to provide more supervision than love.

It is hard to envision either of these incredible intellects and innovators surviving in the modern medical community. Imagine today's Halsted having to explain a two-year hiatus from his practice for psychiatric treatment or being allowed to self-treat cocaine addiction with morphine injections and continue to perform major surgery. Or imagine Freud rising in academia and achieving public acceptance after nearly killing several patients with cocaine overdoses, exhibiting cocaine-induced paranoia and engaging in poorly veiled infidelities. Markel lets us see that, despite the emotional and physical damage wrought by repeated cycles of intoxication, withdrawal, craving and relapse, both of these giants were able to maintain a place in the scientific and medical communities and make a mark on history.

Importantly, An Anatomy of Addiction offers more than just juicy reading. Markel also weaves into his narrative lucid and clear explanations of the psychology and pharmacology of addiction; he provides a clear and well-crafted distillation of a huge volume of science. But what makes this book a must-read are the stories of our intellectual fathers, their journeys into darkness and their stunning achievements despite their struggles with the very real demons of addiction. I recommend this wonderful book for all physicians and scientists.

\section{COMPETING FINANCIAL INTERESTS}

The author declares no competing financial interests. 